\title{
CONTRIBUIÇÕES DA PSICOLOGIA DO TRABALHO PARA O CAMPO TRABALHO E EDUCAÇÃO
}

\author{
CONTRIBUTIONS OF WORK PSYCHOLOGY TO THE FIELD OF WORK AND EDUCATION \\ CONTRIBUICIONES DE LA PSIOLOGÍA DEL TRABAJO PARA EL CAMPO TRABAJO Y EDUCACIÓN
}

VIEGAS, Moacir Fernando ${ }^{1}$

\section{RESUMO}

O objetivo do presente artigo é analisar as possibilidades de contribuição da Psicologia do Trabalho para o campo Trabalho e Educação, tendo como apoio revisão de literatura que contempla especialmente autores espanhóis. O estudo se justifica pela crescente importância dos fenômenos psicossociais relativos às organizações e relações de trabalho e pelas mútuas contribuições para a investigação científica que resultariam de uma melhor aproximação entre esses campos de conhecimento. Para o alcance dos objetivos, discorremos também sobre a presença da Psicologia do Trabalho nas pesquisas e publicações em Trabalho e Educação.

Palavras-chave: Trabalho e educação. Psicologia do Trabalho. Organização do trabalho. Relações de trabalho. Psicologia positiva.

\section{ABSTRACT}

The goal of this article is to analyze the possibilities of the contribution of Work Psychology to the field of Work and Ecdutaion, through the revision of a complete literature that beholds specially spanish authors. The study is justified by the growing importance of the psychosocial phenomena related to the organizations and work relations and through the mutual contributivos to the scientific investigation that would result from a better approximation between these fields of knlowledge. To reach these objectives, we also talked about the presence of Work Psychology in the researches and publications in Work and Education. Keywords: Work and Education. Work Psychology. Work Organization. Labor relations. Positive Psychology.

\section{RESUMEN}

El objetivo del presente artículo es analisar las posibilidades de contibuición de la Psicología del Trabajo para el campo Trabajo y Educación, teniendo como apoyo revisión de bibliografía que contempla especialmente autores españoles. El estudio se justifica por la cresciente importancia de los fenómenos psicosociales relativos a las organizaciones y relaciones de trabajo y por las mutuas contribuciones para la investigación científica que resultarían de una mejor aproximación entre estos campos de conocimiento. Para el alcance de los objetivos, hablaremos tambiém sobre la presencia de la Psicología del Trabajo en las pesquisas y publicaciones en Trabajo y Educación.

Palabras clave: Trabajo y educación. Psicología del Trabajo. Organización del trabajo. Relaciones de trabajo. Psicología positiva.

\footnotetext{
1 Universidade de Santa Cruz do Sul - UNISC - Santa Cruz do Sul - Rio Grande do Sul - Brasil
} 


\section{INTRODUÇÃO}

Nas décadas mais recentes, a Psicologia, e em especial a Psicologia do Trabalho, tem se interessado crescentemente pelo que ocorre nos ambientes de trabalho, ampliando a importância desse campo de conhecimento para as demais áreas que se ocupam do mesmo tema. Autores como Peiró e Ripol (1999) relacionam o aumento da importância da Psicologia do Trabalho ao crescimento do setor serviços, porque, nesse setor, a dimensão subjetiva das relações sociais ocupa lugar de maior destaque. Vale mencionar que mesmo a indústria, conforme Zarifian (1999), funciona cada vez mais nos moldes das relações de trabalho do setor serviços. Assim, como resultado, vivemos uma intensificação dos estudos sobre subjetividade (BENDASSOLLI, BORGES-ANDRADE e MALVEZZI, 2010)

Para Blanch e Cantera (2008), no capitalismo flexível ocorre uma mudança nas formas de subjetivação da experiência de trabalho, do sentido e do valor que se confere ao mesmo, sendo que seu exercício se desloca cada vez mais do esforço físico para o esforço intelectual e emocional. 0 aspecto fundamental, no nosso entendimento, é que o capitalismo flexível colocou em evidência as capacidades subjetivas dos trabalhadores, que se tornaram mais visíveis e objeto de maior atenção da gestão empresarial e do pensamento científico. No que respeita à qualificação, o capitalismo flexível exige capacidade de raciocínio mais complexo, elevando a necessidade de escolaridade da força de trabalho.

Podemos ver o efeito dessa mudança no âmbito na saúde dos trabalhadores, onde, devido também à crescente precarização das relações de trabalho, constata-se o aumento das doenças mentais dos mesmos. Como afirmam Blanch e Cantera (2008, p. 10),

\footnotetext{
O trabalho precário constitui um problema de saúde pública e de vulnerabilidade social de primeira ordem, que comporta para quem o vive uma crise de identidade profissional, de implicação com o emprego, de contrato psicológico e de compromisso organizacional, além de altas doses de mal-estar e insatisfação pela incerteza e inseguridade no emprego e especialmente uma grande dificuldade de planificação da carreira profissional e familiar.
}

Apesar da amplitude alcançada pela atuação e pelos estudos da Psicologia pelos fenômenos relativos ao trabalho, notamos que sua presença nas pesquisas do campo Trabalho e Educação é bem pouco significativa. No âmbito das reuniões anuais da Associação Nacional de Pós-Graduação e Pesquisa em Educação, especificamente no GT Trabalho e Educação, estudos com apoio na Psicologia do Trabalho são praticamente inexistentes, realidade semelhante à verificada nas produções de revistas da área da Educação de qualis A1 e A2, considerando os últimos dez anos. O mesmo podemos constatar em revisão das teses e dissertações sobre trabalho docente na área (2008-2018), onde são bem pouco comuns estudos que busquem apoio naquele campo de conhecimento.

Diante do exposto, o objetivo do presente artigo é analisar as possibilidades de contribuição da Psicologia do Trabalho para o campo de conhecimento Trabalho e Educação. Preocupa-nos 
especialmente as contribuições que o crescimento dos estudos da Psicologia do Trabalho pode trazer para o estudo da problemática do trabalho docente.

Em nossa revisão teórica, daremos destaque à literatura espanhola, sobre a qual nos debruçamos em estudos realizados em nível de pós-doutorado, quando nos dedicamos principalmente aos autores Carlos María Alcover De La Hera, Josep María Blanch e Marisa Salanova, dentre outros pesquisadores espanhóis e latino-americanos.

No texto, iniciamos por situar o âmbito de atuação da Psicologia do Trabalho, tanto em nível profissional como acadêmico. Em seguida, apresentamos considerações desse campo de conhecimento sobre os efeitos psicossociais da atual crise do trabalho. Depois enfocamos a Psicologia Positiva, uma abordagem recente que vem conquistando espaço no estudo dos aspectos psicossociais do trabalho. Por fim, antes das considerações finais, tratamos mais especificamente das relações entre Trabalho e Educação e Psicologia do Trabalho.

Consideramos que se trata de uma primeira aproximação dessa literatura, que, portanto, não tem a pretensão de abranger toda a produção acadêmica da área.

\section{ÂMBITO DE ATUAÇÃO DA PSICOLOGIA DO TRABALHO}

A Psicologia do Trabalho nasce, não por coincidência, no início do século XX, nos Estados Unidos, quando Taylor inicia suas experiências sobre a organização científica do trabalho. Influenciados pelo ambiente positivista, os primeiros psicólogos que aplicaram seus conhecimentos ao trabalho centraram-se em aspectos individuais, como personalidade, inteligência, atitudes e habilidades, com uma metodologia quantitativa (ALCOVER DE LA HERA et al, 2004; BLANCH, 2007).

Com a crescente compreensão do caráter social da Psicologia, nos anos 1930 e 1940 a denominação que se impõe é Psicologia Social do Trabalho. Beléndez (2002) destaca a influência do funcionalismo até pelo menos a década de 1970, quando então a área se apoiava em modelos clássicos e humanistas para a abordagem de fenômenos como o conflito de interesses, deixando de lado aspectos como as relações de poder e entendendo como disfuncionais fenômenos como as greves e o absenteísmo.

Segundo Beléndez (2002), a partir dos anos 1970, com o reconhecimento do trabalho nas organizações de serviços, a denominação que se impõe é Psicologia do Trabalho e das Organizações. Para Blanch, essa mudança marcou também a transição metodológica de um viés marcadamente psicométrico para outro mais pluralista. Porém, conforme Peiró e Ripol (1999), a metodologia quantitativa seguiu predominando.

Conforme vários autores (BLANCH, 2007; DE LA HERA ET AL, 2004; PEYRÓ e RIPOL, 1999) a Psicologia do Trabalho, assim como a própria Psicologia, constitui tanto um campo de conhecimento como de aplicação de conhecimentos ou intervenção, sendo, portanto, uma ciência aplicada. 
Como não poderia ser diferente, dada sua própria denominação, a Psicologia do Trabalho ${ }^{2}$ vê a categoria trabalho como a mais importante em seus estudos. Para Blanch (2012, p. 31), o trabalho constitui, na modernidade capitalista, uma característica fundamental da civilização, constituindo "um modo de produção da vida social, política, cultural e psicológica”. Alcover De La Hera et al (2004, p. 15) afirmam que "a centralidade do trabalho constitui o núcleo axiológico do significado de trabalhar", sofrendo influência dos diferentes contextos históricos.

As investigações da Psicologia do Trabalho revelam que as pessoas costumam sentir-se bem pelo fato de trabalharem, independentemente do grau de satisfação que experimentam. A dimensão psicossocial do trabalho proporciona a construção da identidade, contribuindo decisivamente para a autopercepção que os sujeitos têm de si mesmos. Assim, o trabalho (ou a ausência dele) é o "eixo central que articula e estrutura (ou desarticula e desestrutura) a vida das pessoas e inclusive as sociedades em seu conjunto" (ALCOVER DE LA HERA et al, 2004, p. 269). Ainda que feito sob dominação e alienação, o trabalho é menos deletério que a privação do trabalho. Ele é uma forma de realização do sujeito, "um mediador da emancipação (DEJOURS, 2006, p. 123)" e trabalhar "pode ser a prova eletiva da revelação da vida a ela mesma" (DEJOURS, 2004, p. 33), desde que a subjetividade seja reconhecida e respeitada.

Conforme Blanch (2007, p. 3), a psicologia social do trabalho "se ocupa basicamente de fenômenos e processos psicossociais implicados na atividade e na experiência laborais", onde tem lugar privilegiado a interação do trabalhador com seu entorno de trabalho, compreendendo tanto a produção de documentos que permitam compreender seu funcionamento como "sua aplicação e utilização na solução de problemas básicos ou concretos".

A Psicologia do Trabalho estuda as influências recíprocas entre pessoas, grupos e organizações. Nesse sentido, busca analisar como as pessoas "pensam, sentem e valoram o trabalhar em regime de emprego e que impacto psicossocial produz nelas sua situação de trabalho" ou de não trabalho (ALCOVER DE LA HERA et al, 2004, p. 7). O estudo das condutas e experiências pessoais no trabalho se dá tanto no âmbito individual, como no interpessoal-grupal e no organizacional-social, onde o objetivo imediato é "descrever, explicar e predizer os fenômenos psicossociais que têm lugar nestes contextos, assim como prevenir ou solucionar os problemas que surjam, enquanto seu objetivo último é melhorar a qualidade de vida laboral dos trabalhadores, a produtividade e a eficiência laboral” (p. 22).

Autores como o próprio Alcover De La Hera (2004) destacam a importância do contexto para a compreensão dos fenômenos, sendo ele um elemento chave para entender e interpretar a relação existente entre conduta e processos mentais. Afirmam que é um exercício inútil e perigoso falar do indivíduo em abstrato, de seu comportamento ou do que pensa e o que sente, pois isso equivaleria a acreditar que "as pessoas possuem uma espécie de essência ou de núcleo imanente que é independente dos muitos fatores do ambiente em que vivem” (2004, p. 9, grifos do autor).

\footnotetext{
2 Não ignoramos as diferentes denominações que recebem os campos de conhecimento da Psicologia que estudam o trabalho. Porém, abordar esse tema implicaria ultrapassar as dimensões desse artigo. A título de esclarecimento, afirmamos que os principais autores com os quais trabalhamos identificam-se com o que, no Brasil, denomina-se Psicologia Social do Trabalho.
} 
Os temas de interesse do campo de conhecimento advêm de seus diferentes ramos, que, segundo Blanch (2007), incluem: a) Psicologia do Trabalho propriamente dita, que estuda o trabalho, a forma e as condições em que é realizado, a qualidade de vida e o panorama sociolaboral no que respeita a questões como o emprego e o desemprego; b) Psicologia da Organização, que se preocupa com a conduta coletiva dos trabalhadores como parte de um conjunto organizacional, onde entram questões como cultura e clima, liderança, conflito e negociação e c) Psicologia do Pessoal, que se dedica ao estudo das relações entre trabalhadores e organizações, privilegiando temas como processos de seleção, formação, avaliação, etc.

Já para Borges-Andrade e Pagotto (2010, p. 39), a Psicologia do Trabalho investiga "comportamentos, relações entre pessoas e grupos, disposições, motivos, percepções, crenças, reações, atitudes, significados, valores e sentimentos”, além de práticas relativas à gestão de pessoas. Sobrevivem na atualidade temas clássicos, como significado do trabalho, valores e atitudes laborais e avaliação de pessoal, questões antigas que passaram a um primeiro plano, como saúde no trabalho e qualidade de vida laboral, e processos emergentes, como gestão por competências, empregabilidade, precarização do emprego, fatores de risco psicossocial e exclusão laboral, entre outros (BLANCH, 2007).

Uma das problemáticas de estudo mais relevantes para a Psicologia do Trabalho é o estresse, visto que reúne as relações entre condições de trabalho e saúde e por sua "incidência sobre a qualidade de vida (...), a eficácia, a eficiência, a viabilidade e a sustentabilidade das organizações de trabalho" (BLANCH, 2012, p. 77). Junto com o burnout, o estresse adquire ainda maior importância na conjuntura atual de trabalho cada vez mais precarizado e intenso.

Comentando a produção intelectual da Psicologia do Trabalho, Tonetto et al (2008) apontam que hoje são pouco comuns as publicações sobre funções tradicionais de recursos humanos, tais como recrutamento e seleção, mas que permanecem em grande número os estudos sobre treinamento, agora focados no desenvolvimento de habilidades e competências. Praticamente a metade das publicações da área concentra-se em comportamento organizacional e gestão de pessoas, percebendo-se um crescente interesse por estudos na área trabalho e saúde, onde predominam pesquisas sobre sofrimento psíquico, estresse e burnout.

É interessante notar as disciplinas com as quais a Psicologia do Trabalho se relaciona e o fato de que a Educação, área com a qual está indubitavelmente ligada, nem sempre é mencionada. Alcover De La Hera et al (2004), por exemplo, salientam a necessidade de relações disciplinares com modelos e teorias da Antropologia, Sociologia, Economia, Direito e História. Outros, como Beléndez (2002), destacam o Direito, a Sociologia, a Economia e a Política.

Também na realidade brasileira a Psicologia do Trabalho vem crescendo nas últimas décadas, o que, conforme Gondim, Borges-Andrade e Bastos (2010), pode ser demonstrado pelo fato desse campo de atuação ser ocupado por um quarto dos profissionais da área. Na época da publicação de seu artigo, o campo contava com 18 programas de pós-graduação. 
Em termos da atuação profissional, no imaginário dos trabalhadores é difícil dissociar o profissional da Psicologia do Trabalho da gestão de recursos humanos, envolvido em processos de seleção, formação e avaliação da força de trabalho, o que corresponde a um compromisso histórico com as teorias e práticas de gestão empresariais (ALCOVER DE LA HERA et al, 2004; BORGES, 2010; MARTíNEZ e CASTAÑEDA, 2006). Conforme Bernardo (1998), esse compromisso não é recente, pois já no período anterior à segunda guerra mundial os profissionais seguidores da Escola de Relações Humanas atuavam na minimização e redução dos custos dos conflitos, assim como no aproveitamento e a apropriação da criatividade dos trabalhadores.

Álvarez e Marín (2007, p. 50), referindo-se à Psicologia Organizacional, afirmam que ela possui o papel de tecnologia de poder, "implantada nos espaços empresariais para a produção de certo tipo de subjetividades" visando a construção de trabalhadores autônomos, competentes, responsáveis, comprometidos e com a capacidade de administrar a incerteza. O objetivo é conquistar o trabalhador, alinhando sua subjetividade com a filosofia, os objetivos e os valores empresariais, assegurando a sintonia de seus comportamentos com os ideais da organização.

O constructo psicológico dominante, segundo Crespo e Cerrano (2011), trabalha no sentido de deslocar o significado da categoria "ausência de trabalho" por meio da difusão de conceitos como o de empregabilidade, pondo ênfase no "governo das vontades", de modo a responsabilizar as vítimas da crise por suas dificuldades, fazendo da dependência uma patologia moral.

Porém, como ocorre no pensamento científico em geral, nem todo o campo de conhecimento da Psicologia do Trabalho está comprometido com o status quo e disso é testemunha a literatura que trazemos para este artigo. É preciso considerar que mesmo os profissionais que atuam em organizações empresariais estão inseridos em práticas sociais contraditórias e sua atuação reflete essas contradições.

Assim, Gondim, Borges-Andrade e Bastos (2010, p. 86) destacam que há na Psicologia do Trabalho uma perspectiva crítica em relação à abordagens que contribuem para o amortecimento das contradições da divisão do trabalho. Nessa perspectiva crítica, assume-se "uma postura menos prescritiva sobre qual seria o melhor ser humano, o melhor trabalho e o melhor resultado, e passa-se a descrever como é o trabalho, como este se insere no mundo do trabalho, como produz e em que condições". No âmbito das pesquisas que contribuem para essa compreensão, os autores situam a Psicanálise, a Psicodinâmica do Trabalho e os estudos sobre qualidade de vida no trabalho, o bemestar e a saúde.

\section{EFEITOS PSICOSSOCIAIS DA ATUAL CRISE DO TRABALHO}

A literatura investigada traz importantes contribuições da Psicologia do Trabalho para a compreensão das mudanças atuais do trabalho. Blanch e Ochoa (2012) começam por questionar se é o mesmo trabalhar tendo boas condições de tempo para realização de uma atividade e meios para executá-la bem, com adequadas prevenções de riscos e com um salário digno, que realizar a mesma 
atividade sob pressão constante do tempo, falta de recursos materiais, em condições de alto risco para a saúde e de miséria salarial e contratual.

Quando do predomínio do paradigma taylorista-fordista na organização do trabalho, a estabilidade gerava aspirações e expectativas "centradas em uma vida significativa e normalizada, desenvolvida no seio de uma sociedade salarial e vertebrada por um posto, um contrato, um salário, uma empresa, uma profissão, uma carreira e um sistema de relações de trabalho estáveis" (BLANCH e CANTERA, 2008, p. 94). Nesse contexto, o trabalho, além de sustento material, era a principal fonte de significado e sentido, de emancipação e alienação, além de estruturação psicológica, social e cultural.

Porém, na atualidade do capitalismo, a globalização neoliberal, a inovação tecnológica e a flexibilização organizacional têm alterado os modos de pensar, agir e sentir no trabalho, conferindo-lhe novos significados. Alcover De La Hera et al (2004) destacam a mudança no tipo de pacto social experienciado, no qual se percebem, entre outros aspectos, uma transformação da segurança, do longo prazo, em insegurança; um cenário de emprego estruturável e predizível em um cenário de emprego flexível e ambíguo; de uma carreira profissional dirigida pela empresa para uma dirigida pelo trabalhador; de confiança e investimento mútuos para escassa confiança e muito cinismo. Eles consideram que a precarização atual do trabalho resulta ou potencializa a desigualdade, a desestabilização, a desestruturação, a dualização e a exclusão, diferenciando os trabalhadores que possuem um bom trabalho e os demais, colocados em diferentes graus de trabalho precário.

Estar trabalhando, hoje, não significa a saída da instabilidade, já que a alternativa que atualmente os governos impõem como solução ao desemprego é o trabalho precarizado. A crescente precarização coloca cada vez mais indivíduos em situações de incerteza, de vulnerabilidade, de risco, "que obrigam a viver a cada dia e que dificultam quando não impedem o planejamento de projetos vitais a longo prazo, o estabelecimento de vínculos fortes e a confiança, a lealdade e o compromisso interpessoais e sociais" (ALCOVER DE LA HERA et al, 2004).

Analisando o fenômeno do desemprego, Blanch $(2008,2012)$ aponta uma série de disfunções por ele causadas, dentre as quais destacamos: desorganização do tempo cotidiano, isolamento e vulnerabilidade social, incerteza e deterioração das competências profissionais, além da "fuga" para paraísos artificiais, como o álcool, o tabaco, fármacos e outras drogas.

Uma importante característica da produção flexível abordada na revisão de literatura é a individualização das responsabilidades. Frente à insegurança e a incerteza, cada um deve gerir seu risco, "assumindo as consequências individuais de suas escolhas individuais" (BLANCH e CANTERA, 2008 , p. 90). Para esses autores, a flexibilidade transcende a organização do trabalho, atingindo também as bases culturais do padrão atual de viver e trabalhar.

Na mesma linha de raciocínio, Crespo $(2014,2015)$ chama a atenção para o fenômeno da psicologização do social, traduzida como conversão ou redução de problemas sociais em psicológicos individuais. O fenômeno expressa as atuais contradições da produção capitalista, que, por um lado, necessita da cumplicidade e disponibilidade do trabalhador e, de outro, legitima a precariedade e 
insegurança no trabalho. Conclusão semelhante a de Peiró e Ripoll (1999), que afirmam que as empresas, mesmo sendo incapazes de garantir a estabilidade em longo prazo, exigem dos trabalhadores maior compromisso e elevação da produtividade.

As condições de trabalho atuais colaboram com o descenso do compromisso do trabalhador com a organização (RODRÍGUEZ, 2011), trazendo o risco de ruptura do contrato psicológico ${ }^{3}$. Desse modo, originam-se discursos cujo fim é "reforçar um conceito de sujeito ativo" (CRESPO, 2011, p. 249), porém, num contexto que encaminha cada vez mais para a heteronomia.

A responsabilização individual configura-se, desse modo, como uma estratégia capitalista para transferir ao trabalhador as responsabilidades das mazelas causadas pelo sistema. Segundo o mesmo autor (2011, p. 249), as políticas de emprego atuais

\footnotetext{
coincidem com uma tendência crescente de reforçar o exercício da responsabilidade de si mesmo, segundo a qual cada pessoa teria que organizar de forma autônoma seu próprio projeto de vida e atuar por si mesma (...). Fomenta-se uma concepção normativa da autonomia que ignora o caráter interdependente das relações sociais.
}

Da mesma forma como ocorria quando do predomínio do taylor-fordismo, as estratégias empresariais da produção flexível enfrentam as resistências dos trabalhadores, dado que nem a impotência dos mesmos, nem o poder da gestão, são absolutos. Assim, entre outras tantas formas de enfrentamento, os trabalhadores priorizam algumas tarefas em detrimento de outras, estabelecem limites quantitativos de atividades, tais como número de emails e relatórios, inventam desculpas para ausentar-se no trabalho, delegando, transferindo ou adiando tarefas, etc (BLANCH, 2014).

\section{A PSICOLOGIA POSITIVA E O ENGAGEMENT}

Segundo Blanch (2012), o predomínio da tendência clínica na Psicologia determinou um viés patologista dos estudos sobre o bem-estar no trabalho, que acabou resumido no mal-estar laboral. Levantamentos sobre a produção intelectual da Psicologia do Trabalho revelam que se produziu quinze vezes mais sobre aspectos negativos, tais como distresse, burnout e depressão, do que com o foco em aspectos positivos, como felicidade, satisfação e bem estar (BLANCH e CANTERA, 2008).

Mais recentemente, aparecem indícios de correção desse viés na forma de "enfoques globais que contemplam tanto o polo negativo como o positivo da saúde e bem-estar no trabalho" (BLANCH, 2012, p. 38). Dando como exemplo o burnout, a psicologia positiva questiona se o quadro que se vê nesta síndrome não representaria uma situação “mais ou menos extrema e excepcional, e se não existe outro polo potencialmente positivo e saudável, que funcionaria como seu contrário e seu contrapeso" (BLANCH, 2012, p. 85). O conceito que expressa essa forma de analisar os fenômenos do

\footnotetext{
${ }^{3}$ De La Hera, Martínez-Iñigo e Rodríguez-Mazo (2005, p. 79) definem contrato psicológico como um "sistema de percepções e crenças desenvolvidas pelo empregado e por seu empregador com respeito aos termos que regulam seu acordo de intercâmbio".
} 
trabalho chama-se engagement, o qual Blanch (2012, p. 38) define como "um estado mental positivo, de realização, relacionado com o trabalho, que se caracteriza por vigor, dedicação e absorção".

González, Corte e Rubio (2010, p. 11) conceituam o que denominam de "psicologia organizacional positiva" como "o estudo científico do funcionamento ótimo das pessoas e dos grupos nas organizações, assim como sua gestão efetiva". Eles afirmam que as organizações precisam valorizar não apenas o capital humano, mas também o "capital psicológico", além das "fortalezas pessoais" e capacidades psicológicas dos trabalhadores. Definem "capital psicológico" como "o conjunto de características positivas que aplicamos em nossa vida profissional, as quais, postas a serviço dos contextos de trabalho, podem marcar uma diferença nos resultados que se conseguem".

Salanova (2010, p. 32), uma das principais estudiosas da psicologia positiva, expondo os aspectos básicos da Psicologia da Saúde Ocupacional, afirma que esta utiliza um conceito positivo de saúde que inclui tanto recursos físicos como sociais e pessoais, noção que, segundo a autora, está em sintonia com o conceito proposto pela Organização Mundial da Saúde, que a define como "um estado de bem estar total que inclui o bem estar físico, mental e social, e não a mera ausência de doença ou transtornos".

Para González, De La Corte e Rubio (2010), os estudos sobre burnout têm dado um "giro" em direção aos estudos sobre engagement, influenciado pelo crescimento da psicologia positiva. Eles afirmam que um dos objetivos da psicologia positiva, ao identificar os fatores sustentadores de bem estar profissional e pessoal dos trabalhadores, é descobrir por que existem pessoas e organizações que possuem maior "energia positiva" na relação com o trabalho, assim como a maneira de conseguilo.

Para Blanch (2012), no entanto, os enfoques centrados no engagement contribuem para desviar a atenção sobre os aspectos organizacionais do trabalho, que são naturalizados. Nessa direção, Gernet e Déjours (2009) ressaltam que as práticas que convocam o engajamento dos trabalhadores acabam por negar a subjetividade dos mesmos.

$\mathrm{Na}$ busca dos aspectos mais importantes enquanto "estados subjetivos positivos", as investigações da psicologia positiva apontam uma lista das "raízes da vida positiva", que inclui "amor e intimidade, o trabalho satisfatório, a ajuda aos outros, a cidadania, espiritualidade, liderança" (SALANOVA e LÓPEZ-ZAFRA, 2011, p. 341), entre outros. Para as autoras, é preciso fornecer respostas ao que chamam de "coração" da psicologia da saúde ocupacional positiva, buscando compreender o que caracteriza os trabalhadores e as organizações saudáveis. Defendem que o qualificativo saudável confere às organizações um novo significado, onde o cuidado da saúde de ambos ocupa um lugar central.

A psicologia positiva, se por um lado pode contribuir para pensar formas dos trabalhadores resistirem à crescente intensificação do trabalho, ao objetivar identificar suas "fortalezas", contribui com a gestão empresarial na apropriação de formas de resistência como meio de incrementar a 
produtividade. Parece-nos, inclusive, que a própria convocação ao engagement limita, de saída, as possibilidades emancipatórias.

\section{DIÁLOGOS ENTRE TRABALHO E EDUCAÇÃO E PSICOLOGIA DO TRABALHO}

Como apontamos no início do artigo, o diálogo entre os campos Trabalho e Educação e Psicologia do Trabalho, considerando o conjunto das produções acadêmicas que mencionamos, é bastante incipiente, o que talvez possa ser explicado pela persistente divisão entre áreas do conhecimento. Alguma aproximação começa a ser construída nas últimas duas décadas. Para isso, contribuem de forma significativa estudos que têm como um de seus temas principais a saúde dos professores, os quais, como ocorre com os demais trabalhadores, vivem um aumento da incidência de doenças mentais. Assim, por exemplo, em levantamento da produção acadêmica sobre trabalho docente na educação básica, onde analisou as dissertações e teses produzidas entre 1987 e 2007 , Duarte (2010) constatou o fortalecimento de estudos de temas como a saúde e o mal-estar docente. $\mathrm{Na}$ primeira década do período enfocado (1987-1996) a autora não encontrou estudos sobre estes temas. Já na segunda (1997-2009), encontrou 23 pesquisas.

Os temas da saúde constituem, desse modo, a principal ponte para o diálogo entre os campos de conhecimento da Educação e da Psicologia que estudam o trabalho, o que pode ser verificado também nas teses e dissertações sobre trabalho docente na área da Educação produzidas nos últimos dez anos (2008-2017). Nesse período, podemos constatar aproximações por meio de temáticas como adoecimento, burnout, afastamento, licenças médicas, saúde mental, sofrimento psíquico e mal-estar, geralmente associados à temas clássicos do campo Trabalho e Educação, tais como absenteísmo, organização e condições de trabalho, precarização e intensificação. Desse modo, podemos concluir que as categorias da sociologia do trabalho constituem os canais pelos quais têm conversado Trabalho e Educação e Psicologia do Trabalho.

Porém, nesse mesmo levantamento, constatamos que são raros estudos da Educação que busquem apoio aprofundado na Psicologia do Trabalho, o que é demonstrado, por exemplo, na rara menção a revistas específicas desse campo de conhecimento. Nos poucos estudos que encontramos, a Psicodinâmica do Trabalho ocupa lugar de destaque. Entre os autores, Wanderley Codo e Christophe Dejours são os mais citados, sendo os únicos mencionados na maioria dos trabalhos.

Apesar da Educação nem sempre ser mencionada como uma disciplina fundamental nos estudos da Psicologia do Trabalho, sua importância é evidente, na medida em que o campo de atuação profissional está permanentemente envolvido com a formação dos trabalhadores. Tonetto et al (2008), por exemplo, mencionam as contribuições da educação para a pesquisa na Psicologia do Trabalho e no seu desafio de pensar formas de construção de habilidades adequadas às necessidades dos trabalhadores.

A nosso ver, as mudanças na organização e nas relações do trabalho, ao exigirem dos trabalhadores conhecimentos de maior complexidade, configuram-se como as principais responsáveis 
pelo novo significado da Educação na atuação profissional e na pesquisa acadêmica de psicólogos e educadores. Como afirmam Alcover De La Hera e Rodríguez (1999), nas novas formas de trabalho os administradores da organização deverão "ampliar os níveis de racionalidade" (p. 179), a fim de que consigam lidar ao mesmo tempo com informação, conhecimentos mais complexos, conflitivos e mais abstratos. Segundo Carbo e Segovia (2010), o compartilhamento do conhecimento entre os membros de uma organização é um processo central para entender tanto a inovação como a capacidade de aprendizagem.

Alcover De la Hera et al (2004, p. 184) caracterizam o trabalho baseado em conhecimento como sendo "não rotineiro, emergente, variado, único, não linear, interdependente, incerto e dinâmico". Para trabalhar desse modo é necessário enfrentar, segundo os mesmos, três desafios: 1) o técnico, que implica tornar visível o conhecimento tácito dos trabalhadores para que seja discutido, compartilhado, sistematizado e aplicado; 2) o pessoal, que significa que os trabalhadores devem aprender a trabalhar de modo que todos possam conhecer esse trabalho anteriormente à sua conclusão e revisão e 3) o organizacional, que implica a garantia de espaços de aprendizagem e de apoio à colaboração.

Tais mudanças têm incrementado substancialmente a importância dos processos de aprendizagem, constituindo parte importante das estratégias de gestão empresariais: "cada vez menos processos de aprendizagem são deixados ao azar ou às relações informais e a cada dia mais ações de aprendizagem programadas ou demandadas pela organização formam parte de ações globais e integradas com a política estratégica da organização" (ALCOVER DE LA HERA et al, 2004, p. 345), tendência essa que tende a intensificar-se, tanto no que diz respeito à amplitude quanto ao ritmo. Para os autores, como o trabalho exige aprender continuamente, a tendência é de uma maior expressividade da formação ${ }^{4}$.

Outra aspecto importante é o deslocamento da aprendizagem na empresa "para uma aprendizagem orientada ao trabalho, mas cuja responsabilidade recai sobre o empregado" (ALCOVER DE LA HERA et al, 2004, p. 345). Na lógica da produção flexível, são os indivíduos que devem assumir a qualificação, tanto para a entrada como para a permanência no mercado de trabalho, como exemplificam conceitos como empregabilidade ou autoformação, os quais expressam um processo de externalização de funções antes assumidas pela gestão de recursos humanos ou pela formação inicial.

Um dado que mostra a crescente importância da Educação para a Psicologia do Trabalho é o aumento, nas últimas décadas, do interesse em nível internacional pelas pesquisas sobre cognição e trabalho (BORGES-ANDRADE e PAGOTTO, 2010). Estudos sobre aprendizagem, com destaque para as investigações sobre os efeitos de treinamento e desenvolvimento e autoaprendizagem no posto de trabalho, estão em segundo lugar entre os temas de pesquisa em revisão de literatura sobre Psicologia do Trabalho realizada pelos autores.

Outro campo importante é a Psicologia dos Grupos. Frente à crescente necessidade de compartilhar informações, os trabalhadores têm que realizar um número cada vez maior de tarefas

\footnotetext{
${ }^{4}$ Os autores definem a formação no trabalho como um processo de aprendizagem sistemático implementado pela gerência da empresa no sentido de obter mudanças permanentes nos conhecimentos.
} 
intelectuais e cognitivas, como "solucionar problemas, tomar decisões, emitir juízos e realizar inferências" (ALCOVER DE LA HERA e RODRÍGUEZ, 1999, p. 179). A principal consequência dessa mudança é uma perspectiva que contempla os grupos como "processadores de informação", onde estão implicadas questões como o grau e o modo em que as informações são compartilhadas (de forma verbal ou não verbal), assim como a influência desse compartilhamento nos resultados da produção.

Para Alcover De La Hera et al (2004, p. 345), não há dúvidas de que o ambiente de trabalho envolve permanentemente situações de aprendizagem:

O trabalho implica a execução de tarefas, a realização de determinadas funções e o desempenho de papéis. Tudo isso, sem dúvida, supõe a aquisição de conhecimentos e o desenvolvimento de habilidades, assim como de valores, de significados e de símbolos que constituem a cultura da organização, e, portanto, converte os contextos de trabalho em cenários de aprendizagem.

O que está em questão nas relações e na organização do trabalho na atualidade é a formação de uma nova cultura do trabalho, processo no qual estão implicados psicólogos e educadores que têm sua atuação profissional ou sua pesquisa voltadas ao trabalho. Para Crespo e Serrano, a criação e o governo de determinados tipos de sujeitos e mentalidades é um pré-requisito para a existência das relações de trabalho capitalistas. E entre os valores que hoje fazem parte desse processo de formação dos trabalhadores incluem-se, segundo eles, uma "cultura da brevidade, de exigência de reinvenção constante, de permanente adaptação e de diversificação dos tempos sociais" (2011, p. 247), os quais, segundo eles, podem resultar no debilitamento do sujeito.

\section{CONSIDERAÇÕES FINAIS}

A organização do trabalho capitalista é um espaço de relações sociais eminentemente contraditórias que opõem classe trabalhadora e capitalistas. A nosso ver, não é possível entender as diversas práticas educativas que aí se desenvolvem sem levar isso em consideração.

A formação no âmbito das empresas e escolas oferece aos trabalhadores, contraditoriamente, a possibilidade de desenvolverem suas capacidades e desse modo a perspectiva de manter seu emprego ou de ocupar postos mais qualificados no mercado de trabalho, funcionando também como fator de motivação. Essa questão constitui um dilema para profissionais e pesquisadores da Educação e da Psicologia do Trabalho críticas, envolvidos com a formação de trabalhadores.

No caso da Educação, uma problemática central é a compreensão das formas como os trabalhadores desenvolvem, ao longo de sua trajetória profissional, uma cultura que visa não somente se adaptar às mudanças organizacionais mas também fazer prevalecer sua visão de mundo nas relações sociais de trabalho. 
A literatura que revisamos para esse artigo apresenta uma compreensão crítica da realidade social, pois valoriza a abordagem contextual, correlacionando dimensões psicossociais, econômicas, políticas e culturais em seu estudo dos fenômenos do trabalho. Além disso, traz contribuições para uma perspectiva emancipatória da sociedade, ao considerar as contradições da organização e das relações de trabalho capitalistas.

Concluímos, assim, que a Psicologia do Trabalho traz contribuições fundamentais para o entendimento das práticas educativas nos locais de trabalho e, desse modo, para o campo de pesquisa Trabalho e Educação, particularmente quando se apoia na Sociologia do Trabalho, cujas categorias analíticas são uma tradição no campo Trabalho e Educação.

Em relação especificamente à psicologia positiva, entendemos que, mesmo com as críticas que apresentamos, suas investigações, na medida em que trazem não só os aspectos negativos, mas também os positivos, podem contribuir para o entendimento e fortalecimento das formas de enfrentamento dos trabalhadores aos problemas de saúde e ao sofrimento psíquico imposto pela crescente precarização e intensificação do trabalho.

\section{REFERÊNCIAS}

1. ALCOVER DE LA HERA, C.; MARTINEZ ÍNIIGO, D.; RODRIGUEZ MAZO, F.; DOMÍNGUES BILBAO, R. Introducción a la psicología del trabajo. Madrid: McGraw-Hill, 2004.

2. AlCOVER DE LA HERA, C. M.; RODRÍGuEZ, F. G. Influencias de las nuevas formas de flexibilidad organizacional sobre los equipos de trabajo. Revista de Psicología General y Aplicada, v. 52, n. 2-3, p. 177-201, 1999. https://dialnet.unirioja.es/descarga/articulo/2498311.pdf.

3. ALCOVER DE LA HERA, C. M.; MARTINEZ ÍNIIGO, D.; RODRIGUEZ MAZO, F. “¿Cuánto tiempo trabajaremos aquí?" Antigüedad en la organización y características de los contratos psicológicos en empleados de call/contact centers. Revista de Psicología Social, v. 20, n. 1, p. 73-91, 2005.

4. ÁLVAREZ, C. M. G.; MARÍN, L. M. C. Tecnologías empresariales del yo: la construcción de sujetos laborales en el contexto del trabajo inmaterial. Universitas Psychologica, v. 1, p. 49-58, 2007, http://www.scielo.org.co/pdf/rups/v6n1/v6n1a06.pdf.

5. BELÉNDEZ, M. Aportaciones de la psicología social y de la psicología del trabajo y de las organizaciones al campo de las relaciones laborales. [mimeo]. Universidad de Alicante, 2002.

6. BENDASSOLLI, P. F.; BORGES-ANDRADE, J. E.; MALVEZZI, S. Paradigmas, eixos temáticos e tensões na Psicologia do Trabalho no Brasil. Estudos de Psicologia, v. 15, n. 3, p. 281-289, 2010. http://www.scielo.br/pdf/epsic/v15n3/a08v15n3.pdf. 
7. BERNARDO, João. Economia dos conflitos sociais. São Paulo, Cortez, 1991.

8. BLANCH, J. M. Quality of working life in commoditized hospitals and universities. Papeles del Psicólogo, v. 35, n. 1, p. 40-47, 2014. http://www.papelesdelpsicologo.es/English/2320.pdf. Trabajar y bienestar. In: (Org.). Teoría de las relaciones laborales. Barcelona: FUOC, 2012.

La doble cara (organizacional y personal) de la flexibilización del trabajo. Desafíos, responsabilidad y agenda de la psicología del trabajo y de la organización. Perspectivas en Psicología, v. 6, n. 11, p. 11-26, 2008. social: perspectivas socioculturales. México-Barcelona: Anthropos-UAM, , p. 210-238, 2007.

12. BLANCH, J. M.; CANTERA, L. M. Subjetivación del trabajo en el capitalismo flexible. In: MENDES, A. M. (Ed.). Trabalho e Saúde: o sujeito entre emancipação e servidão. Curitiba: Juruá, p. 89-101, 2008.

13. BLANCH, J. M.; OCHOA, P. J.; SAHAGÚN, M. A. Resignificación del trabajo y de la profesión médica bajo la nueva gestión sanitaria. In: ANSOLEAGA, E.; ARTAZA, O.; SUÁREZ, J. (Eds.). Personas que cuidan personas: dimensión humana y trabajo en salud. Santiago de Chile: OPS/OMS, p. 165-175, 2012.

14. BORGES, L. de O. A psicologia do trabalho e das organizações no Brasil floresce? Estudos de Psicologia, v. 15, n. 3, p. 277-279, 2010. http://www.scielo.br/pdf/epsic/v15n3/a07v15n3.

15. BORGES-ANDRADE, J. E.; PAGOTTO, C. do P. O estado da arte da pesquisa brasileira em psicologia do trabalho e organizacional. Psicologia: teoria e pesquisa, v. 26, n. especial, p. 37-50, 2010. http://www.scielo.br/pdf/ptp/v26nspe/a04v26ns.pdf.

CARBO, G. T.; SEGOVIA, A. O. Antecedentes organizacionales y personales de las intenciones de compartir conocimiento: apoyo, clima y compromiso con la organización. Revista de Psicología del Trabajo y de las Organizaciones, v. 26, n. 3, p. 235-253. 2010. http://www.redalyc.org/articulo.oa?id=231322132006. 26, n. 2, p. 271-279, 2014. http://www.scielo.br/pdf/psoc/v26n2/a04v26n2.pdf. 
18. CRESPO, E. Una nota sobre el sujeto de la identidade. Papeles del CEIC, n. 1, p. 1-10, 2015. http://www.ehu.eus/ojs/index.php/papelesCEIC/article/viewFile/14688/13177.

19. CRESPO, E.; SERRANO, A. Regulación del trabajo y el gobierno de la subjetividad: la psicologización política del trabajo. In: OVEJERO, A.; RAMOS, J. (Org.) Psicología Social Crítica. Madrid: Biblioteca Nueva, 2011, p. 246-263.

DÉJOURS, C. Aliénation et clinique du travail. Actuel Marx, n. 39, p. 123-144, 2006. https://www.cairn.info/revue-actuel-marx-2006-1-page-123.htm.

Subjetividade, trabalho e ação. Revista Produção, v. 14, n. 3, p. 27-34, 2004. http://www.scielo.br/pdf/prod/v14n3/v14n3a03.pdf.

DUARTE, A. A produção acadêmica sobre trabalho docente na educação básica no Brasil: 19872007. Educar em Revista, n. especial 1, p. 101-117, 2010. http://www.scielo.br/pdf/er/nspe_1/05.pdf.

23. GERNET, I.; DEJOURS, C. Évaluation du travail et reconnaissance. Nouvelle Revue de Psychosociologie, v. 8 , p. 27-36, 2009. https://www.cairn.info/revue-nouvelle-revue-depsychosociologie-2009-2-page-27.htm.

24. GONDIM, S. M. G.; BORGES-ANDRADE, J. E.; BASTOS, A. V. B. Psicologia do trabalho e das organizações: produção científica e desafios metodológicos. Psicologia em pesquisa, v. 4, n. 2, p. 84-99, 2010. http://pepsic.bvsalud.org/pdf/psipesq/v4n2/v4n2a02.pdf.

25. GONZÁlEZ, A. M. C.; DE LA CORTE, C. M.; RUBIO, J. M. L. Engagement. un recurso para optimizar la salud psicosocial en las organizaciones y prevenir el burnout y estrés laboral. Revista Digital de Prevención, n. 1/2010. http://rabida.uhu.es/dspace/handle/10272/5468?show=full.

26. MARTÍNEZ, Á. E.; CASTAÑEDA Z., D. I. Estado actual de la investigación en psicología organizacional y del trabajo en Colombia. Acta Colombiana de Psicología, v. 9, n. 1, p. 77-85, 2006. http://www.redalyc.org/pdf/798/79890107.pdf.

27. PEIRÓ, J. M.; RIPOLL, P. Psicología de las organizaciones: cambios recentes, retos y perspectivas. Revista de Psicología Geral e Aplicada, v. 52, n. 2-3, p. 169-176, 1999. https://dialnet.unirioja.es/descarga/articulo/2498305.pdf.

28. RODRÍGUEZ, J. J. V. Los tipos de contratación laboral y sus implicaciones en el contrato psicológico. Pensamiento Psicológico, v. 9, n. 16, p. 171-182, 2011. http://www.scielo.org.co/pdf/pepsi/v9n16/v9n16a12.pdf. 


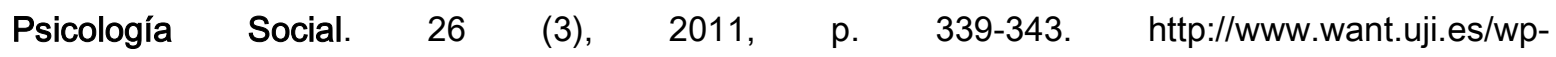
content/uploads/2017/03/2011_Salanova-L\%C3\%B3pez-Zafra.pdf.

31. TONETTO, A. M.; AMAZARRAY, M. R.; KOLLER, S. H. GOMES, W. B. Psicologia organizacional e do trabalho no brasil: desenvolvimento científico contemporâneo. Psicologia \& Sociedade, v. 20, n. 2, p. 165-173, 2008. http://www.scielo.br/pdf/psoc/v20n2/a03v20n2.pdf.

ZARIFIAN, P. Mutación de los sistemas productivos y competencias profesionales: la produción industrial de servicio. In: El modelo de competencia y los sistemas productivos. Oficina Internacional del Trabajo. Montevideo: Cinterfor, 1999.

\section{Moacir Fernando Viegas}

Graduado em Pedagogia Séries Iniciais pela Universidade Federal do Rio Grande do Sul, mestrado em Educação pela Universidade Federal do Rio Grande do Sul, doutorado em Educação pela Universidade Federal do Rio Grande do Sul e pós-doutorado em Psicologia do Trabalho na Universidad Autónoma de Barcelona. Atualmente é professor adjunto da Universidade de Santa Cruz do Sul, atuando na graduação e na pós-graduação stricto sensu, fazendo parte, nessa última, da linha de pesquisa Educação, Trabalho e Emancipação, do mestrado e doutorado em Educação.

Como citar este documento:

VIEGAS, Moacir Fernando. Diálogo entre trabalho e educação e psicologia do trabalho. Reflexão e Ação, Santa Cruz do Sul, v. 26, n. 3, nov. 2018. ISSN 1982-9949. Disponível em: <https://online.unisc.br/seer/index.php/reflex/article/view/12160>. Acesso em: 20 nov. 2018. doi:https://doi.org/10.17058/rea.v26i3.12160. 